\title{
Intellectual Property Rights and Innovation in Africa
}

\author{
Noël Bouopda ${ }^{1}$, Gael Fokam ${ }^{2}$, Lionel Douanla ${ }^{3}$ \\ ${ }^{I}$ Dschang School of Economics and Management, University of Dschang, Dschang, Cameroon \\ ${ }^{2}$ Faculty of Economics and Management, University of Dschang, Dschang, Cameroon \\ ${ }^{3}$ Université de Yaoundé2 Soa, Cameroon
}

\begin{abstract}
The purpose of this study is to assess the effect of intellectual property rights on technological innovation in 24 African countries, 7 of which belong to OAPI, 11 to ARIPO and 6 countries not belonging to any property rigths organization. This study differs from other studies with the use of the World Innovation index instead of the use of inputs and outputs approaches. The number of patents demand deposited by resident and the number of commercial brands is used to capture Intellectual property rights. Using first difference panel data, results show a none significant effect of patents on innovation in Africa and positive and significant effect of commercial brand on innovation. However, the study by Zone shows a positive and significant effect of intellectual property rights on innovation in ARIPO countries.
\end{abstract}

Key words: Patent, commercial brand, innovation.

\section{INTRODUCTION}

$\mathrm{T}$ he incentive for innovation is the main justification for the existence of intellectual property rights. If we look at the questions in counterfactual terms, we could, for example, ask ourselves if technological innovation can be possible without intellectual property rights. Considering the objective of encouraging innovation, Pajak, (2011) proposes several economic mechanisms aimed at encouraging innovation. These include innovation subsidies, increasing the absorption capacity of technologies, creating a conducive environment to innovation, the purchase of patents by the Government to place it in the public domain.

However, these mechanisms seem to be much more complementary than substitutable for the incentive which would provide the advantages of a legal property right over the intellectual. Indeed, Schumpeter (1939) justifies the need for an institutional monopoly on intellectual creations as being the only real means of inciting innovation because of the particular nature of this good. In addition, full involvement of the public authorities without the private sector's own will could lead to inefficiency in the results obtained and a mismatch between the technology needs of users and the results of research driven by the public authorities.

Empirically, the salient facts seem to show that state choices are in favor of adopting the legal protection of intellectual property rights as a means of encouraging research and innovation through the right to monopoly. Indeed, 36 countries out of 53 in Africa are members of a regional intellectual property organization and the great African powers such as Egypt, Morocco, South Africa, Tunisia and Nigeria have their own national offices in the region.
However, the hope-for results seem mixed with regard to the rank that African countries occupy in the world rankings in terms of innovations. The first innovative country in Africa occupies the 63 rd place in the world, while the 2 nd occupies the 70th place. Expected effects of protection by intellectual property rights seem to be conditioned by other factors that many African countries have not yet integrated. What about it in reality? Do intellectual property rights have positive effects on innovation in Africa or not? What is the optimal intellectual property policy? Would membership in area such as OAPI $^{1}$ or ARIPO ${ }^{2}$ influences this result?

This study aims to provide answers to its various questions through an analysis of the effect of intellectual property rights on innovation in Africa. This article is organized in five sections. After the introduction, sections 2 and 3 emphasize, respectively on the critical review of the literature and on methodology. Section 4 presents the results of the study after which the economic and social policy recommendations are developed in section 5 which also serves as conclusion.

\section{CRITICAL REVIEW OF THE LITERATURE}

\subsection{Criticism of theoretical aspects}

The historical analysis of the construction of intellectual property rights undeniably making innovation at the heart of the issue of protection. Indeed, the ancestor of the patents formerly granted in Italy, then called "patentvenezela", was intended to encourage the holder of new knowledge by granting him an annual operating monopoly on all know-how. Many decades later, the link between intellectual property and innovation is still far from clear and still fuels much debate.

Joseph Alois Schumpeter \& Fain, (1951) finds, among other things, that the market structure favorable to innovation is the monopoly which he believes is the only way to provide incentives for research and development that is the source of innovation. For him, the monopoly rent that a creator hopes to have is the only real way to get him involved in the creative activity. Thus, the incentive to innovate

\footnotetext{
${ }^{1}$ OAPI : African Intellectual property Organization with Cameroon Niger, Mali, Benin, Ivory Coast, Burkina Faso and Senegal as member countries included in this study (Zone2).

${ }^{2}$ African Regional Intellectual Property Organization with Kenya, Lesotho, Malawi, Mozambique, Namibia, Tanzania, Ouganda ; Zimbabwe, Zambia, Botswana and Ghana as member countries included in this study (Zone3). This study also include countries which do not belong to any group like Tunisia, Egypt, South Africa, Moroco, Ethiopia and Nigeria (Zone1).
} 
becomes an issue of crucial importance for economic expansion, which results from the creation of new products and processes, their commercial exploitation, their diffusion and their widespread use (Crifo-Tillet, 1999). However, since the innovation-friendly monopoly market structure suggested by Schumpeter cannot be achieved naturally, the author suggests resorting to institutional monopoly. The link between Schumpeterian innovation and intellectual property is thus highlighted in this work where the author demonstrates that the innovation which is the work of the innovative entrepreneur could not exist without a monopoly structure of the market supposed to reassure this last on the impact of its creation (Crampes et al., 2006). Thus, IPRs in general and patents in particular by granting the innovator a temporary monopoly to enable him to make profitable his creative activity promotes innovation. Thus, even if the distortions in the knowledge market, created by the monopoly conferred by the patent have often been denounced as a hindering the dissemination of knowledge and the well-being of consumers who will have to suffer from monopoly prices, Ziemnowicz, (1942) has the merit of having shown that it is essential for technological innovation to take place in a monopolistic environment (Crifo-Tillet, 1999).

The link between intellectual property and innovation is also anchored in the theory of transaction costs in the sense that the acquisition of an intellectual property right gives rise to costs that must be taken into account in an economic calculation. Having to define the need to use it. Empirical authors like Papageorgiadis \& Sharma (2016) have also shown, through an index that captures the transaction costs arising from IPRs, that when they decline, the incentive to innovate is greater. The influence of IPR on innovation must therefore take into account transaction costs.

The economic theory of transaction costs owes its development to the work of economists such as (Akerlof George, 1970; Coase, 2012; Pagano, 1993). It finds its origin in the work of Coase (1937) and is understood as a cost linked to an economic transaction carried out in a market. Coase questions the role of the market and the reasons that push firms to organize themselves internally so as not to resort to the market. Although an analysis which does not grant the market its central role as an ideal framework of exchange is contrary to classical analysis, the author thrives in his reflections by insinuating that resorting to the market causes additional costs that he then calls transaction costs. However Lakhal (999) finds that internalization also comes at a cost which is that of growth limited to a certain level. Indeed, according to the author, the use of the market does not hinder the growth of the company while with internalization, there is a level of growth that the firm cannot access. There is therefore a critical moment when the size of the firm makes it more profitable to resort to the market despite the existence of transaction costs. Internalization as well as access to the market are two opposable modes of coordination of economic activities and there is an optimal size of the firm from which the choice of the market is the most profitable and, this size corresponds to the point of equilibrium between the internal transaction cost and the cost of going to the market. Lakhal (999) therefore contradicts liberal economists for whom the market is the only effective economic institution, by showing that there are circumstances where the execution of transactions within firms is done at lower costs than the market.

North $(1987,1989)$ is an institutional economist who defines institutions as being: "the rules of the game in a society or more formally, it is the humanly designed constraints that determine human interactions. Consequently, institutions structure the incentives for human exchanges in the political, economic and social fields and aim to reduce uncertainty in everyday life ". For North, institutions are central to a country's economic growth and development, which comes true when it creates an environment for incentives, transactions and investment. And, in the case of an unfavorable institutional environment, it follows underdevelopment and poverty. North's contribution to the theory of transaction costs is to establish a link between the institutional environment and transaction costs. He thus defines the idea that economic development depends on the capacity of established institutions to reduce transaction costs and facilitate the division of labor (North, 2005). This logic is clearly justified today in terms of intellectual property with regard to the institutions that administer it under the basis of rules designed with the aim of reducing uncertainty and facilitating transactions between economic agents among themselves or between owners of protectable innovation and society.

Theory of externalities can also be used to explain the link between intellectual property and innovation. In fact, according to the pioneering work of Agbloyor et al., (2014), the existence of an externality refers to a situation in which the production or consumption of an economic good by one agent influences the well-being of another. without this interaction being the subject of an economic transaction. Thus, in the case of the knowledge market that supports all innovation, the externality arises from the fact that it can be produced by some and freely used by others. Belleflamme, (2008) attributes this state of affairs to the particular nature of knowledge and denounces the negative influences that these characteristics of non-rivalry and non-exclusivity have on the incentive for innovation. However, for authors such as Belleflamme (2008) and Ballet et al. (2009), a system of private property rights by means of intellectual property, and more precisely of the patent, is a solution to this problem. Indeed, intellectual property through the monopoly it confers on the right holder encourages inventors to invest in research/development for more creativity. Thus, the accumulated stock of knowledge creates positive externalities for future research and for social welfare. Likewise, intellectual property facilitates the dissemination of technologies through its information and knowledge 
dissemination system. Intellectual property law therefore proposes a system that should make it possible to preserve the positive externalities generated by the dissemination of knowledge for the benefit of innovation, while ensuring its appropriation by innovators, alone or in a research team.

\subsection{Critical analyses of empirical work}

The analysis of the impact of intellectual property on innovation has been the subject of much debate among economists. Indeed, while some find a positive relationship in it, others find it insignificant and even ambiguous. In addition, a large body of literature has also focused on the reasons or factors that influence the relationship between intellectual property rights, patents and innovation. These factors require attention to the extent that they would sometimes justify the failure to achieve the intended effects of protection.

\subsubsection{Empirical review of a positive relationship between intellectual property and innovation}

Pfister \& Combe (2001) analyzed the effects of strengthening intellectual property rights in southern and northern countries using the model developed by (Helpman, 1992). According to this model, the effects of strengthening human rights Intellectual property depends on three factors namely the initial imitation rate before said reinforcement, the relative labor supply in the south as well as the innovation rate. by recalling the three traditional effects of intellectual property rights, in particular the incentive for innovation, the development of research intended to meet the needs of developing countries; the dissemination of information which prevents the duplication of research and development efforts and favors the Cumulative innovation, the authors find that strengthening IPR has positive effects on innovation in the short term. However, these effects diminish the North's propensity to innovate in the long run as, in the absence of imitation, it becomes more profitable to produce the same goods rather than create another.

Chen \& Puttitanun (2005) analyzed the link between intellectual property rights and innovation in developing countries using panel data modeling on 64 developing countries. The authors then develop a theoretical model making it possible to analyze the factors of choice between national innovation, the imitation of foreign technologies and their relationship with intellectual property rights. They lead to the result that a high level of innovation leads to an increase in the volume of IPRs. However, the relationship is not monotonous. It is initially descending more ascending. The empirical analysis using a panel model is made over a period from 1975 to 2000, with variables such as the patent to measure innovation, the Ginarte and Park protection index to measure the DPI, GDP / HBT to measure the level of development of countries, the enrollment rate of the population at the tertiary level to understand the education factor, the volume of international trade in $\%$ of GDP to measure trade openness and the population for measure the size of the market. The results obtained show a stronger impact of IPRs on innovation in countries with a higher level of development. Moreover, the results of the empirical model confirm the relationship between intellectual property and the economic development of developing countries obtained in the theoretical model.

Oloukol"li \& Senou (2016) analyzed the nature of the relationship between intellectual property rights, innovation and added value in different African countries namely Benin, Ivory Coast, Senegal, Kenya, South Africa and Tunisia. By using an "Auto Regressive Distributed Lag" approach and leads to the result according to which the relation between IP and added value is complex and ambiguous because if in Benin, in Kenya in South Africa and in Tunisia, this relation is positive and it is negative in Ivory Coast and in Senegal. The authors nonetheless conclude that IPRs have a positive influence on innovation because IPRs encourage investment in Research / Development and therefore innovation insofar as these allow companies to lower R / D costs. Furthermore, the authors find that IPRs promote the expansion of labor and increase labor productivity. At the same time, innovation itself, its use and the possibility of imitating it are sources of added value and economic growth.

Mohamed (2017) studied the relationship between the patent and the economic growth of Tunisia driven by innovation over a period from 1970 to 2010 . He started from the principle of endogenous growth of Romer (1990) according to which innovation with patent protection with an unlimited lifespan leads to technical progress and economic growth. For this purpose, it uses the following variables: growth rate of the Gross Domestic Product (GDP) to measure Tunisia's economic growth, the number of patent applications that it delays by one year to measure its effect in time and capture innovation through its output.

the result obtained shows a statistically insignificant relationship at the 5\% threshold between GDP and patent filing. which means an absence of relation in the sense of Granger between the GDP and the patent filings. However, the introduction of the research / development variable as a research input in a robustness study led to establish the existence of a positive and significant relationship at the $10 \%$ threshold, between research / development and the patent, which means that investments in research / development encourage innovation and the filing of patents. Likewise, the positive link and significance between the growth rate of GDP and patent filings delayed by a period shows that today's innovations, measured by the patent in t, find their application at the earliest in $t+1$. The patent can then be considered as a vector of innovation in the service of growth.

NAPO \& AMBAGNA (2014) measured the relationship between intellectual property and the growth of 11 OAPI member countries. The authors define two channels of transmission of growth through innovation, which they measure using patent filings and foreign direct investment. 
The eleven countries are divided into two large groups namely the most advanced countries in the area such as the Ivory Coast, Senegal, Cameroon, Gabon and the group of least developed countries such as Chad, Benin, and the Central African Republic. The authors use a VAR modeling on panel data which they justify by the fact that the OLS, MCG or maximum likelihood methods usually used in this kind of study do not make it possible to solve endogeneity problems and do not take into account the effects of reciprocity between the variables. The authors come to the result that an increase in patent filing leads to a small amplitude increase in shortterm filings. Its effect will diminish until it wears off over time. Likewise, the relationship between patent and FDI is positive. This means that intellectual property rights and more specifically patents positively influence innovation and FDI. However, this result is verified only in the most developed countries of the zone and confirms the thesis according to which the impact of intellectual property depends on the stage of development of the countries (Ginarte \& Park, 1997; Schneider, 2005).

\subsubsection{Empirical review on a controversial relationship between intellectual property and innovation}

The existence of a difference between the effects of IPRs on innovation within the countries of the North calls to question the possible reasons for such a disparity. At first glance, the difference would come from a state policy, a policy of the inventors in terms of protection or even the socio-economic environment of the countries.

Kabla (1994) conducted a study on patents as an indicator of innovation and examines to what extent and under what conditions innovation is linked to a patent filing. She then analyzes the profile of the French depositor on the basis of the French survey on innovation for the period from 1986 to 1990. Using a Logit model and the Wald test, the author comes up with the result according to which the sector of activity plays a determining role in the decision to patent or not. To this end, it finds that high and medium technology sectors such as aeronautical construction, electrical and household appliances, pharmaceuticals, chemicals and automobile construction have a high probability of resorting to patent protection. This could be explained by the fact that sectors with a large and medium technological base also require more intense research and significant resources in terms of research / development. To this end, the results obtained cannot be left within the reach of possible counterfeiters. Thus, legal protection would make it possible to claim the rights of the protected person before a court. Another possible explanation is that in technological sectors changes are rapid and innovations frequent, therefore the race for the primacy of invention and the right of the exploited is also fierce; the need to be able to have this primacy and to oblige other potential users of the invention requires prior legal ownership, hence the recourse to the patent. The author also proves that the size and nature of the innovation are important elements in the decision to patent. In short, for
Kabla (1994) the profile of the French depositor over the period 1986-1990 is as follows: a large company belonging to a high or medium technology sector, with product innovations rather than process, and whose share of the turnover of the innovative product is relatively high.

In the same Bussy et al. (1994) used information from the European patent database collected at the National Institute of Industrial Property (INPI) from the European Patent Office (EPO) to draw up a profile of the French depositor. And just like Kabla (1994) they come to the conclusion that companies that file patents in France belong to high-tech industries. They are large and have the necessary financial means to bear the costs of protection. The industry of choice for patent applicants is explained by the fact that research evolves exponentially in high-tech sectors and the use of intellectual property rights allows the innovator to limit competition and to stand out protect against possible infringement proceedings. In fact, in such sectors, an innovator may be prohibited from using his invention by an informed applicant who has gained the upper hand. The authors further note that occasional depositors protect themselves in all the countries of the organization while the more accustomed depositor designates from the start of the protection process the most economically important European countries. This demonstrates the strategic vision of the patent.

Arundel \& Kabla (1998) conducted another study based on 600 European companies on the choice of the mode of protection of their innovation and establish that the decision to patent is strongly linked to the sector of activity. The authors confirm the thesis according to which not all innovations are patented and is a strategic choice justified for several reasons. They find that out of the 600 companies studied, only $36 \%$ of product innovation has been patented against $25 \%$ of process innovation. Moreover, concerning the link between the patent filing and the sector of activity, the high technology sectors such as chemistry, pharmacy, electronics and electrical engineering, mechanical construction, and aeronautics, have a greater likelihood of protecting their innovation by filing patents. To this end, the study finds that the pharmaceutical industries have patented their innovations up to $79 \%$.

\section{METHODOLOGY}

\subsection{The empirical model to be tested.}

In this study, the hypotheses are tested using a model derived from the Teritlak (2016) associated with a dynamic panel model.

The specification retained within the framework of this study is as follows:

$I I G_{i t}=\alpha I I G_{\text {tt }-1}+\beta_{1}$ brevet $_{i t}+\beta_{2}$ marque $_{\text {it }}+\beta_{3}$ orvert $_{\text {it }}+\beta_{4}$ inflation $_{\text {it }}+\beta_{5}$ pib $_{\text {it }}+\beta_{6}$ Rule $_{\text {it }}+v_{i}+\varepsilon_{i t}(1)$

Where

$I I G_{i t}$ The overall innovation index in country i in year $\mathrm{t}$; 
$I I G_{i t-1}$ The overall innovation index in country $\mathrm{i}$ in year $\mathrm{t}-1$; brevet $_{i t}$ Patent filings in country i in year $\mathrm{t}$;

marque $_{i t}$ Trademark registrations in country $\mathrm{i}$ in year $\mathrm{t}$; ouvert $_{i t}$ International openess in country i in year $\mathrm{t}$;

inf lation $_{i t}$ The inflation rate in country $\mathrm{i}$ in year $\mathrm{t}$;

$p i b_{i t}$ GDP per capita in country $\mathrm{i}$ in year $\mathrm{t}$;

Rule $_{i t}$ The estimate of the legal rules in country $\mathrm{i}$ in year $\mathrm{t}$;

$v_{i}$ The specific individual effect;

$\varepsilon_{i t}$ The error term.

\subsection{Estimation technique and Data source}

A dynamic model is a model in which one or more lags of the dependent variable appear as explanatory variables. Unlike dynamic panel GMMs, standard econometric techniques such as OLS do not allow unbiased estimates of such a model to be obtained, because of the presence of the lagged dependent variable to the right of the equation. The GMM method is based on the orthogonally conditions between the lagged variables and the error term, both in first differences and in level. When the dynamic model is expressed in first differences, the instruments are level, and vice versa (Elbir et al., 2012).

The validity of the selected instruments can be confirmed or denied, from the Sargan test. There are two variants of the dynamic panel GMM estimator: the first difference GMM estimator and the system GMM estimator. For this study, we use the one step GMM first difference estimator, but the one step system estimator will be used to confirm our results.

The first difference GMM estimator of Arellano and Bond (1991) consists in taking for each period the first difference of the equation to be estimated in order to eliminate the individual specific effects. We obtain:

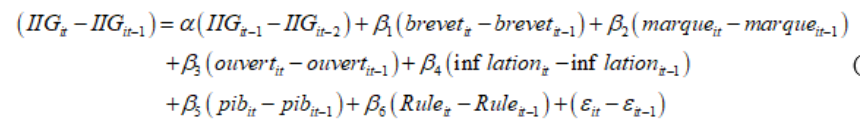

The datas used in this study are from WIPO 2019 and from the World Bank Development indicator 2019.

\section{ESTIMATIONS RESULTS}

We find it useful to first present the result of the overall estimate and then the result of the estimate by area.

Table1 : Overall estimate

\begin{tabular}{|c|c|c|c|c|}
\hline \multirow{2}{*}{$\begin{array}{c}\text { Variables } \\
\text { IIG }\end{array}$} & \multicolumn{2}{|c|}{ GMM in first difference } & \multicolumn{2}{c|}{ GMM in System } \\
\cline { 2 - 5 } & Coefficients & Probability & Coefficients & Probability \\
\hline IIGL1 & $.6434081 * * *$ & 0.000 & $.7169781 * * *$ & 0.000 \\
\hline brevet & .009923 & 0.273 & .0008095 & 0.892 \\
\hline
\end{tabular}

\begin{tabular}{|c|c|c|c|c|}
\hline Marque & $.0008844 * * *$ & 0.001 & $.0007105^{* * *}$ & 0.003 \\
\hline Ouvert & .1058951 & 0.235 & $.1560858^{*}$ & 0.071 \\
\hline Pibd & .0009179 & 0.557 & .0013272 & 0.541 \\
\hline Inflation & -.1277313 & 0.280 & -.1616936 & 0.230 \\
\hline Rule2 & $-.2114112 * *$ & 0.011 & $-.1345824 * * *$ & 0.001 \\
\hline Constante & - & - & $-7.960783 *$ & 0.094 \\
\hline $\begin{array}{c}\text { Nomber of observations }=240 ; \text { Wald } \\
\text { chi2(7) = 388.8 }\end{array}$ & $\begin{array}{c}\text { Nomber of observations }= \\
264 ; \text { Wald chi2(7) }= \\
575.32 \\
\text { Number instruments }=61 ; \text { Prob > } \\
\text { chi2 }=0000\end{array}$ & $\begin{array}{c}\text { Number of instruments }=72 ; \\
\text { Prob > chi2 }=0.0000\end{array}$ \\
\hline
\end{tabular}

Source: The author using stata12 software

The symbols $* * *, * *$ and $*$ denote significance at the $1 \%, 5 \%$ and $10 \%$ thresholds respectively.

The results of the estimate show a positive and significant relationship at the $1 \%$ level between the global index and innovation and the same index lagged by one period. This is justified by the fact that this index takes into account both the different innovations and the system in which they are developed as well, the different elements of the system which cannot change suddenly overnight, have influences on each other. Indeed, the method of calculating the GII takes into account variables such as education, infrastructures, patents, publications which are put in place over time, hence the influence of the GII t- 1 on the GII t. Likewise, innovation is obtained as a result of a set of means set up. Which means are spread over time in terms of funding, study, resources. Thus, work undertaken on a certain date can produce results only after a certain number of times, hence the existence of an inter-temporal link between the different GIIs.

The estimate by GMM in first difference revealed the existence of a link between trademark registration and innovation of the order of 0.008844 , significant at the $1 \%$ level. This result means that branding positively and significantly affects innovation in African countries. This is in line with the logic defended by Remi Lallement (2009) according to which the brand is preferred to the patent in contexts where technological innovations are less and not very radical. Descriptive statistics indeed show a preference for brand protection within African countries and the estimation results show that this protection positively influences innovation. Brand preference and its positive influence on innovation could therefore be justified by the very nature of the innovations encountered in African countries. Lallement (2010) uses the example of French SMEs to point out that the patent seems more suitable for technological innovations and much more radical than continuity. Small-scale or continuity innovations, just like commercial or organizational innovations, seem to be better protected by distinctive signs including trademarks, industrial designs and models. In addition, Martin-Bariteau (2013) noted a theoretical relationship between the brand and the incentive to innovate and indicating that the patent is more suitable for the protection of inventions and that innovation which assumes a marketable application is better protected by the brand. 
The results of the first difference estimate show a positive relationship between the patent and the innovation, however the said relationship is not significant. This result, although contrary to theory and to legal texts, therefore the TRIPS Agreement or the Bangui Agreement according to which intellectual property would have positive effects on innovation is consistent with a good number of empirical works that have at best revealed a non-Significant -relation, explained by the level of economic development of the countries concerned. Indeed, Duguet \& Lelarge (2004) have demonstrated a positive relationship between patents and product and not process innovations. However, a test of robustness by the generalized moments in a system as mentioned in the following table confirms the results obtained according to which the patent and the innovation have an insignificant relationship while the brand has a positive and significant influence on the innovation in African countries.

These same results show a positive but not significant relationship with the openness of countries to international trade, GDP as well as inflation. This means that the fact for a country to be exposed to international trade or to live in autarky has no effect on its level of innovation within African countries. This result is contrary to the theory of Angresano \& others (1997) according to which the countries most exposed to international trade are more able to benefit from the diffusion of technologies (Sweet \& Eterovic Maggio, 2015). The diffusion of technologies can lead, among other things, to skills development through imitation or reverse engineering, savings in research and development time and resources, as well as productivity gains. The development of human resources through the improvement of their skills, productivity gains and research and development are factors in favor of innovation. The result, however, shows the absence of a direct relationship between openness to trade and innovation as measured by the Global Innovation Index.

Moreover, the insignificance of the GDP variable which measures the level of development of countries seems ambiguous and is contrary to the thesis of Ginarte and Park (1997), Branstetter et al. (2006) or Sweet and Eterovic (2015) for whom the nature of relationship between patent and innovation depends on the level of development of the country in question. The more developed the country, the more effectively it is able to take advantage of intellectual property and enable it to play its role in innovation

The governance indicator shows a negative and significant relationship between the rules of rights and innovation within the countries of the study. This will mean that rules of rights and an overly strict legal environment negatively influence innovation in Africa. This result seems contrary to the theory which would like that the respect of the rules of rights constitutes a motivation for the possible innovators who would like to be reassured that their investments are preserved in the event of infringement or lawsuit. However, this situation could be justified by the fact that the informal sector occupies a considerable part of the economy of many African countries. Indeed, they have not yet expected a sufficient level of development to diminish the importance of this sector. To this end, overly strict tariff rules would negatively influence the informal sector in these countries and hamper innovation and growth in these countries.

The results of the system estimates confirm those obtained in the first difference in the influence of lagging GII, brand, GDP inflation as well as governance. However, the results show a positive relationship and significant at the $10 \%$ threshold between commercial opening and innovation. This last result is consistent with the theory that international trade will serve as an instrument for the diffusion of technology Angresano \& others (1997) that can allow imitation, improvement of skills and be a source of mobilization of resources to boost Innovation activity of local businesses.

An estimate of the link between intellectual property and innovation by area yield to the following results.

Table2 : result of the estimates in first difference by Area

\begin{tabular}{|c|c|c|c|}
\hline \multirow{2}{*}{$\begin{array}{c}\text { Variables } \\
\text { IIG }\end{array}$} & \multicolumn{3}{|c|}{ GMM in first Différence } \\
\cline { 2 - 4 } & Zone1 & Zone2 & Zone3 \\
\hline IIGL1 & $.7573684 * * *$ & $.5188052^{* * *}$ & $.7169497 * * *$ \\
\hline brevet & -.0015338 & .0070367 & $.0911364 * * *$ \\
\hline Marque & $.0003719 * * *$ & $.0014132^{* * *}$ & .0002525 \\
\hline Ouvert & $.2109855^{* *}$ & .0700102 & .1320654 \\
\hline Pibd & .0002883 & $.0119397 * * *$ & $.0032501 * *$ \\
\hline Inflation & -.0186915 & .0403068 & -.1888339 \\
\hline Rule2 & -.1567263 & -.1980146 & -.0974315 \\
\hline Nomber of observations & 60 & 70 & 110 \\
\hline Number of instruments & 51 & 54 & 61 \\
\hline Prob > chi2 & 0.0000 & 0.0000 & 0.0000 \\
\hline Arellano-Bond test & AR(1) & AR(1) & AR(1) \\
\hline
\end{tabular}

Source: The author using stata12 software

The symbols $* * *, * *$ and $*$ denote significance at the $1 \%, 5 \%$ and $10 \%$ thresholds respectively.

\subsection{Effect of patents by area}

The patent has an insignificant influence within OAPI member countries as well as in Tunisia, South Africa, Nigeria, Egypt, Morocco and Ethiopia. While the relationship between patents and innovation within ARIPO member countries is positive and significant. However, the first group of countries that are part of zone 1 are countries with the highest level of innovation in Africa, while those in zone 2 have relatively low levels. The results obtained in zone 1 and 2 are similar to those obtained in the overall estimate and could be explained by the policies of the different countries in terms of innovation and protection. However, they are contrary to both theoretical and empirical literature according to which a higher initial level of development leads to better 
effects of intellectual property (Ginarte \& Park, 1997; Schneider, 2005; Sweet \& Maggio, 2015). Indeed, the most developed countries in terms of GDP per capita are Botswana, South Africa, Namibia, Tunisia, Morocco, Malawi, Egypt, Nigeria, Ghana.

Thus, the results obtained in zone 1 are not in line with those of Ginarte and park (1997), scheneider (2005), Sweet and Eterovic (2015) because the countries of the zone have a relatively higher level of development and innovation, and we would have expected that the patent would have more impact on innovation and growth in these countries than in low-income countries such as Niger, Benin, Burkina Faso. However, the study conducted by Ginarte \& Park (1997) also specifies that intellectual property rights have a positive impact from a certain level of development, in which case a strengthening of these rights could be beneficial. The authors therefore recommend developing protection policies according to the level of development. This could justify the results obtained in the sense that the countries in the study as a whole have probably not yet reached the level required for patent protection to benefit their innovation activity.

The countries of zone 2, for their part, have the lowest levels of development and the insignificance of the influence of patents is justified insofar as the countries have not yet reached a level of development sufficient to be able to validly take advantage of the repercussions of the patent according to (Ginarte \& Park, 1997; Sweet \& Eterovic Maggio, 2015). However, countries in zone three which includes relatively developed countries such as Botwana, Namibia, Ghana as well as poor countries such as Malawi and Mozambique and Uganda demonstrate a positive and significant relationship. This result would have been consistent with theory if the developed countries of the zone had considerable influence on the whole region. However, only an estimate by country could better justify the results, which as they stand seem ambiguous.

In short, the analysis of the influence of the patent on innovation by OAPI, ARIPO and outside zones seems ambiguous. A possible source of this ambiguity could be the size of the sample, which is not uniform by area, or the quality of the variables retained. However, this ambiguity was also found in similar studies by (Oloukol"li \& Senou, 2016; Papageorgiadis \& Sharma, 2016).

\subsection{Effect of trademark by zone}

The results of the estimation of the influence of trademark protection by zone reveal a positive and significant relationship at the $1 \%$ level in zones 1 and 2 . This means that trademark filings in these zones lead to an increase in innovation. These results are in line with those obtained during the overall estimate and corroborate the thesis according to which the brand is an intellectual property right which positively influences innovation (Martin-Bariteau, 2013). However, this relationship is also positive for zone 3 countries but it is not significant for those same countries which had where the relationship between intellectual property through patents and innovation has been positive.

Overall, this result, which seems ambiguous insofar as the differences in the analysis of the relationships between patent, brand and innovation cannot be explained by other factors such as the level of development of countries (since the influence of GDP is positive in all three zones but significant only in zones 2 and 3). Likewise, inflation, force of law or openness are largely irrelevant in the different study area and appear to have no effect on innovation. However, at least one of the intellectual property rights considered by the study (patent or trademark) has a positive and significant impact on innovation in the different areas; which could lead to conclude to a positive impact of intellectual property on innovation within the OAPI zone, ARIPO and the countries made up of Tunisia, Nigeria, South Africa, Ethiopia, Egypt and Morocco.

\section{CONCLUSION AND RECOMMENDATIONS}

In short, although economic theory as well as the texts of intellectual property laws have noted a positive influence of intellectual property on technological innovation, the empirical link between IP and technological innovation on all study country was found to be insignificant. Indeed, although the brand has been shown to have a positive influence, it does not have a direct influence on technological innovation insofar as technological innovation which is even protected by the patent. Lallement (2010) in fact raises a greater influence of the brand for the protection of nontechnological innovation than for technological innovation, the latter having as its primary objective to protect the commercial aspect of innovation and therefore, has no direct link with its technical nature. However, this result could suggest that innovation in all of these countries is much more of a non-technological origin or of lesser scope to be influenced by the patent.

These results, although contrary to economic theory on the ability of IPRs to be able to stimulate innovation, agree with those obtained by Ginarte and Park (1997), Scheneider (2005), Sweet and Eterovic (2015), Oloukol"li \& Senou, (2016) who found different levels of influence by country development level, with an insignificant influence at best in underdeveloped countries indicating that in a primary stage of development, countries need more imitation than IPRs. Intellectual property, which by its monopoly slows down imitation, then presents itself as an obstacle to the faculty of technological innovation in the countries of the South.

Thus, African countries should in their current stage of development seek to get the best part of intellectual property by valuing property rights other than patents, in this case utility models like the countries of 'Asia, trademarks, or plant variety certificates. 


\section{REFERENCES}

[1] Agbloyor, E. K., Abor, J. Y., Adjasi, C. K. D., \& Yawson, A (2014). Private capital flows and economic growth in Africa: The role of domestic financial markets. Journal of International Financial Markets, Institutions and Money, 30, 137-152.

[2] Akerlof George, A. (1970). The Market for VLemonsV: Quality Uncertainty and the Market Mech $1 \%$ anism. The Quarterly Journal of Economics, 84(3), 488.

[3] Angresano, J., \& others. (1997). The Political Economy of Gunnar Myrdal. Books.

[4] Arundel, A., \& Kabla, I. (1998). What percentage of innovations are patented? Empirical estimates for European firms. Research Policy, 27(2), 127-141.

[5] Ballet, J., Koffi, K. J.-M., \& Komena, K. B. (2009). Comanagement of natural resources in developing countries: The importance of context. Économie Internationale, 4, 53-76.

[6] Belleflamme, P. (2008). Economics of Interoperability: Competition vs. Innovation, DIW: Université Catholique de Louvain.

[7] Branstetter, L. G., Fisman, R., \& Foley, C. F. (2006). Do stronger intellectual property rights increase international technology transfer? Empirical evidence from US firm-level panel data. The Quarterly Journal of Economics, 121(1), 321-349.

[8] Bussy, J.-C., Carpentier, C., \& Kabla, I. (1994). Les entreprises françaises à l'heure du brevet européen. Economie et Statistique, 275(1), 55-70.

[9] Chen, Y., \& Puttitanun, T. (2005). Intellectual property rights and innovation in developing countries. Journal of Development Economics, 78(2), 474-493.

[10] Coase, R. H. (2012). The firm, the market, and the law. University of Chicago press.

[11] Crampes, C., Encaoua, D., \& Hollander, A. (2006). Competition and intellectual property in the European Union. Edward Elgar.

[12] Crifo-Tillet, P. (1999). L'analyse de l'innovation dans les modèles de croissance endogène. Revue Française d'économie, 14(2), 189221.

[13] Duguet, E., \& Lelarge, C. (2004). Les brevets incitent-ils les entreprises industrielles à innover? Economie et Statistique, 380(1), 35-61.

[14] Elbir, D., Goaied, M., \& others. (2012). Are External Financial Liberalization and Corruption Control Substitutes in Promoting Growth? Empirical Evidence from MENA Countries. Journal of Statistical and Econometric Methods, 1(2), 53-64.

[15] Ginarte, J. C., \& Park, W. G. (1997). Determinants of patent rights: A cross-national study. Research Policy, 26(3), 283-301.

[16] Helpman, E. (1992). Innovation, imitation, and intellectual property rights. National bureau of economic research Cambridge, Mass., USA.

[17] Kabla, I. (1994). Un indicateur de l'innovation: le brevet. Economie et Statistique, 275(1), 95-109.

[18] Lakhal, S. (1999). Vers une approche formelle d'aide a la decision dans l'entreprise reseau. Universite Laval.

[19] Lallement, R. (2010). Droits de propriété intellectuelle et positionnement concurrentiel des entreprises: bilan des nouvelles pratiques et éléments de comparaison franco-allemande. Innovations, 2, 11-34.

[20] Martin-Bariteau, F. (2013). La marque au service de l'innovation (Brand as a Tool for Innovation). Droit et Innovation, Aix-EnProvence, Presses Universitaires d'Aix-Marseille.

[21] Mohamed, M. (2017). Brevet d'invention et croissance économique: une analyse dans le cadre de l'économie tunisienne durant la période 1970-2010. International Journal of Scientific \\& Engineering Research, 8(1), 1953-1961.

[22] NAPO, S., \& AMBAGNA, J. J. (2014). La protection des droits de propriété intellectuelle est-elle source de croissance économique dans les pays africains?

[23] North, D. C. (1987). Institutions, transaction costs and economic growth. Economic Inquiry, 25(3), 419-428.

[24] North, D. C. (1989). Institutions and economic growth: An historical introduction. World Development, 17(9), 1319-1332.

[25] Oloukol"|i, L., \& Senou, M. (2016). Intellectual Property Rights and Innovation: Implications for Added Value Creation in Africa. Journal of Economics, Management and Trade, 1-8.

[26] Pagano, M. (1993). Financial markets and growth: an overview. European Economic Review, 37(2-3), 613-622.

[27] Pajak, S. (2011). La protection de la propriété intellectuelle et l'innovation: contributions empiriques et théoriques. Télécom ParisTech.

[28] Papageorgiadis, N., \& Sharma, A. (2016). Intellectual property rights and innovation: A panel analysis. Economics Letters, 141, $70-72$.

[29] Pfister, É., \& Combe, E. (2001). Le renforcement international des droits de propriété intellectuelle. Economie Internationale, 1, 6381.

[30] Romer, P. M. (1990). Endogenous technological change. Journal of Political Economy, 98(5, Part 2), S71--S102.

[31] Schneider, P. H. (2005). International trade, economic growth and intellectual property rights: A panel data study of developed and developing countries. Journal of Development Economics, 78(2), 529-547.

[32] Schumpeter, Joseph A. (1939). Business Cycles. A theoretical, historical, and statistical analysis of the capitalist process.(Vol. I und II). McGrawl-Hill Book Company. Inc. New York and London.

[33] Schumpeter, Joseph Alois, \& Fain, G. (1951). Capitalisme, socialisme et démocratie. Payot Paris.

[34] Sweet, C. M., \& Eterovic Maggio, D. S. (2015). Do stronger intellectual property rights increase innovation? World Development, 66, 665-677. https://doi.org/10.1016/j.worlddev.2014.08.025

[35] Sweet, C. M., \& Maggio, D. S. E. (2015). Do stronger intellectual property rights increase innovation? World Development, 66, 665677.

[36] Teritlak, M. (2016). Determinants of innovation in developing countries: A panel generalized method of moments analysis. Jurnal Ekonomi Malaysia, 50(2), 93-105.

[37] Ziemnowicz, C. (1942). Joseph A. Schumpeter and innovation. Socialism and Democracy, 82. 